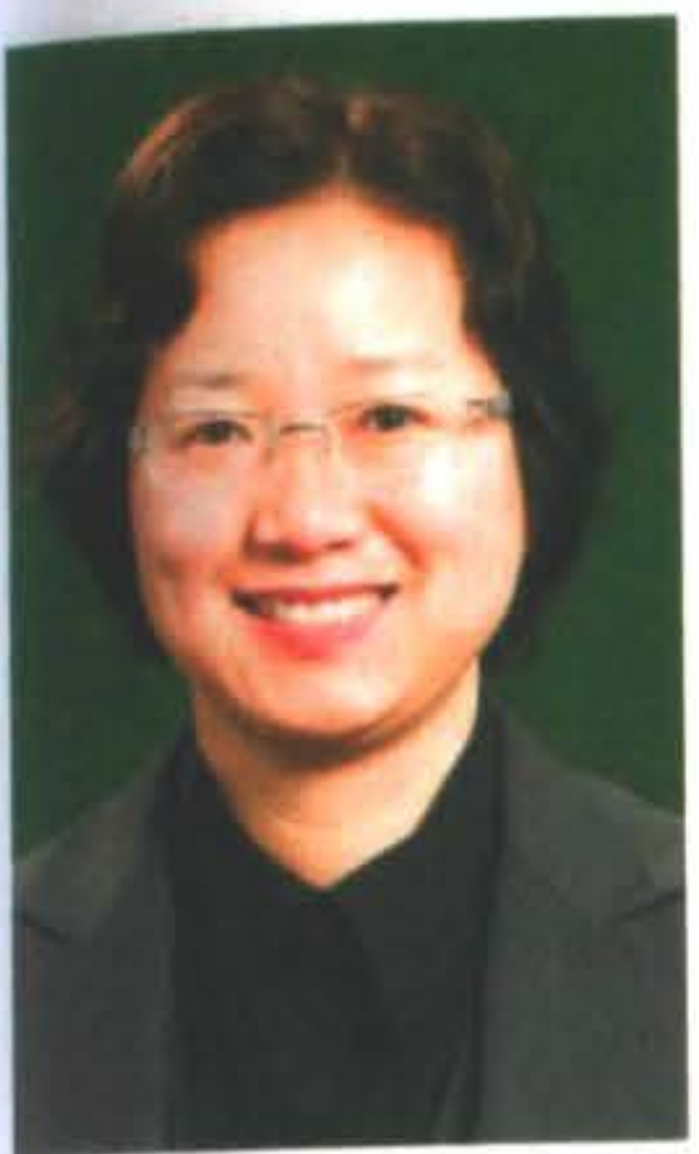

\title{
DOES LABOUR MARKET \\ ACHIEVEMENT MATTER FOR \\ THE WELLBEING OF \\ AUSTRALIAN IMMIGRANTS? \\ CULTURE AND GENDER DIFFERENCES
}

\author{
Weiping Kostenko
}

University of Melbourne

\begin{abstract}
This study explores the Australian immigrants' job-life relationship by simultaneously estimating a bivariate ordered probit random effects panel model. We found that discrepancies between career goals and employment reality play a central role. The study also explores the characteristics of immigrants who are likely to have stronger job concerns. Non-western male immigrants are among them. They are more disadvantaged in the labour market and have lower life satisfaction compared to their Western counterparts, while this situation improves with duration in Australia. Also, immigration age is found to be crucial for this adjustment process. For female immigrants, the results suggest that the well-educated female migrants' subjective wellbeing is impeded by struggling over work-family balance.
\end{abstract}

\section{Introduction}

Measures of wellbeing add a valuable perspective in evaluating a nation's success apart from economic indicators such as GDP. It has been included in the the Organisation for Economic Co-operation and Development (OECD) list of social indicators. Australia is a major migration destination country, with almost one-quarter of the resident population ( 4.8 million out of 20.3 million people) born overseas. ' A high level of subjective wellbeing is an indicator of successful assimilation of immigrants into Australian life, which will contribute to the harmony of a multi-cultural society. Gaining employment is a crucial step in settling into Australia, thus studying joint labour market and wellbeing assimilation is conducive to understand how well immigrants fare in the Australia.

Diener (1984) summarises the research approaches in subjective wellbeing into two categorises: "bottom-up" and "top-down". This study adopts an integrative perspective that unites theses two approaches through Michalos's (1985) Multiple Discrepancies Theory. ${ }^{2}$

Standard economic theories typically rely on actual life circumstances to study subjective wellbeing, which restricts a deeper understanding of human wellbeing. In fact, subjective wellbeing is an area explored more extensively by psychologists. In his review, Diene (1984) distinguishes between "bottom-up" and "top-down" processes. In the former, overall life satisfaction is seen as being determined by satisfaction in different basic domains of life, such as finance, family, health and work. Yet after decades of research, psychologists have come to realize that these external factors often have only a modest impact on wellbeing reports, in that people adapt to their level of resources (Brickman and Campbell, 1971; Diener et al., 1999; Lucas et al., 2003).

Subjective wellbeing is often strongly correlated with stable personality traits. which assumes that the global features of personality influence the interactions an individual has with the world, and it affects all domains of an individual's life. For example, Diener et al (2003) shows that personality dispositions, such as extraversion, neuroticism, and self-esteem, can markedly influence levels of subjective wellbeing.

Michalos's Multiple Discrepancies Theory considers subjective wellbeing as a measure of what reality consequences follow from different combinations of perception, beliefs, feeling and actions. It can serve as a useful device for combining "bottom-up" and "top-down" approaches. Michalos (1985) also reveals that the gap between desired goals and one's actual situation is the best direct predictor of satisfaction comparing to the gap between previous experience and one's actual situation, and the gap between a social comparison group's situation and one's actual situation. Pugliesi (1995) argues that the social bonds established via employment are related to greater life 
satisfaction, and the rewards attached to these social bonds include financial, emotional and informational resources. On the other hand, an extensive survey of Lyubomirsky \& Ross (1997) suggests that happy individuals appear to secure "better" jobs. However, this does not necessary mean that being happy with life will lead to a good job. It is more likely than not that the types of personality which are more commonly found in happy people are also preferable labour market traits. Thus the econometric methodology applied to study the relationship between work domain and life satisfaction should be able to disentangle the direct casual effect and the personality effect. Treating labour market attainment as endogenous to subjective wellbeing, the correlation between the individual effects of them can accommodate aspiration theory, which Michalos's finds to have the most superior predictive power for subjective wellbeing. Fulfilling one's aspiration via achieving career goals would give one a sense of competence or mastery. Indeed, Andrew and Withey (1976) find that personal efficacy is the strongest predictor of life satisfaction.

On the one hand, labour market achievement along with other domains, such as wealth, family and health, directly contribute to overall life satisfaction. On the other hand, individual career goals that are related to personality traits and culture background influence the interactions that the reality of labour market outcome has with subjective wellbeing. So two individuals with the same observable measures in all domains may have very different self-reported subjective wellbeing as they have different goals. A bivariate ordered probit random effects panel model is applied to explore this potentially endogenous job-life relationship that is implied in this unobserved interactions. Using a large-scale longitudinal Australian national survey (HILDA), the intra-personal variations can be estimated with repeated observation of the same individual, which capture the impacts of unobserved personal traits on life satisfaction and labour market attainment. Moveover, the correlation of these individual effects capture the interactions of the work domain and life satisfaction that is influenced by unobserved individual career goals. This model allow us to disentangle the direct contribution of labour market attainment to life satisfaction and the indirect job-life relationship that is influenced by individual specific goals and other personal traits. Also, this model avoids estimation biases caused by potential endogeneity of labour market attainment in subjective wellbeing.

Also, an important objective of this study is to explore the role culture plays in immigrants' labour market and wellbeing assimilation and how culture influences their values regarding employment and occupation. Culture influences the goals people choose, and commitment to goals is most conducive to happiness when those goals are valued by the culture to which the individual belongs (Diener et al, 2003). More than a decade after the Multicultural Act (1989) was introduced in Australia, migration to Australia represents a trend of increasing share of Asians and decreasing share of Europeans (ABS, 2007) Immigrants from different source countries may bring different work values and individualism/collectivelism culture. With the changing Australian population composition and a government embracing multi-culturalism it is thus interesting to explore whether the disparities between the Western and the non-Westem in employment occupational development and wellbeing are still significant in Australia, and how these disparities are brought about by different work values held by cultures of individualism and collectivism. In addition, male and female migrants demonstrate different patterns in labour market and life assimilation, and they are studied independently.

This study aims to contribute to the current literature by linking immigrants' labour market and wellbeing assimilations, and explore the culture and gender differences in this regard. The advanced econometrics model employed allows both the objective circumstances used by economists and the subjective personal factors emphasized by psychologists to be exactly measured. Under such a framework, the adjustment experiences of immigrants in labour market and life in Australia are explored, with particular attention to the culture influences on these adjustment processes.

\section{Statistical Model}

A system of bivariate endogenous ordered Probit models with random effects for panel data is specified to estimate the effect of immigrant labour market performance on their life satisfaction where the labour market outcomes are allowed to be determined endogenously. Formally, the latent utility $L_{i t}^{*}$ of endogenous labour market outcome of the $i$ th person in time period $t$ is determined by:

$$
L_{i t}^{*}=\alpha x_{i t}+\varepsilon_{L, i t} ; i=1, \ldots, N ; t=1, \ldots, T .
$$

where $x_{i t}$ is a vector of exogenous covariates that represent general individual characteristics and human capital endowments, such as education, work experience and English ability. $\alpha$ is the related coefficient vector, and $\varepsilon_{L, i t}$ is the error term. The unobservable $L_{i t}^{*}$ is related to the observable ordered discrete variable $L$ via the following mapping:

$$
L_{i t}=\left\{\begin{array}{lc}
0(\text { Unemployed }) & \text { if } L_{i t}^{*} \leq 0 \\
1(\text { Unskilled job }) & \text { if } 0<L_{i t}^{*} \leq \mu_{L} \\
2(\text { Skilled job }) & \text { if } \mu_{L}<L_{t t}^{*} .
\end{array}\right.
$$

Let $S_{i t}^{*}$ be a latent variable that is proportional to the level of life satisfaction of the $i$ th person in time period $t$, which is modelled via the latent equation:

$S_{i t}^{*}=\beta^{\prime} z_{i t}+\gamma_{1} L 1_{i t}+\gamma_{2} L 2_{i t}+\varepsilon_{S, i t} ; i=1, \ldots, N ; t=1, \ldots, T$. 
where $z_{i t}$ denotes a vector of exogenous covariates that represent general individual characteristics and major life domains, such as family, housing and health. The individual's occupational attainment in the work domain is assumed to be endogenous, with dummy variables, $L 1_{i t}=I\left(L_{i t}=1\right)$ and $L 2_{i t}=I($ Lit $=2)$, indicating the attainment of unskilled and skilled jobs, respectively. The reference category is unemployed. $\beta, \gamma_{1}$ and $\gamma_{2}$ are parameters and $\varepsilon_{S . i t}$ is the error term. The latent variable $S_{i t}^{*}$ is mapped to the observable indicator variable $S$ via

$$
S_{t t}= \begin{cases}0 \text { (Dissatisfied }) & \text { if } S_{i t}^{*} \leq 0 \\ 1(\text { Neutral }) & \text { if } 0<S_{i t}^{*} \leq \mu_{S} \\ 2 \text { (Satisfied }) & \text { if } \mu_{S}<S_{i t}^{*} .\end{cases}
$$

With repeated observations for each individual in a longitudinal data set, we assume an error component structure with the time-invariant error component and time-variant error component:

$$
\begin{aligned}
& \varepsilon_{S, i t}=u_{S, i}+v_{S, i t}, \\
& \varepsilon_{L, i t}=u_{L, i}+v_{L, i t} .
\end{aligned}
$$

$u_{S, i}$ and $u_{L, i}$ are time-invariant and reflect the unobserved individual-specific characteristics that have impacts on person $i^{\prime}$ s subjective wellbeing and labour market performance, respectively. To define a random effects model, we also assume $u_{S, i}$ is unrelated to $z_{i t}$ and $u_{L, i}$ is unrelated to $x_{i t}$. We assume $u_{S, i}:$ i.i.d. $N\left(0, \sigma_{S}^{2}\right)$ and $u_{L, i}$ : i.i.d. $N\left(0, \sigma_{L}^{2}\right) . \sigma_{S}^{2}$ and $\sigma_{L}^{2}$ capture the magnitude of intra-personal variation of subjective wellbeing and labour market outcomes, respectively. For the random error terms, we assume $v_{S, i t}$ : i.i.d.N $(0,1)$ and $v_{L, i t}$ : i.i.d. $N(0,1) \cdot u_{S . i}$ and $v_{S, i t}$ are assumed independent, and so are $u_{L, i}$ and $v_{L, i t}$. These assumptions impose an equal correlation restriction ${ }^{3}$ on the error terms $\left(\varepsilon_{S, i t}\right.$ and $\left.\varepsilon_{L, i t}\right)$ across all individuals. The above restrictions can be written as:

$$
\begin{gathered}
E\left[u_{S} \mid X, Z\right]=E\left[v_{S, i t} \mid X, Z\right]=E\left[u_{L} \mid X, Z\right]=E\left[v_{L, i t} \mid X, Z\right]=0 ; \\
\operatorname{Var}\left[v_{S, i t} \mid X, Z\right]=\operatorname{Var}\left[v_{L, i t} \mid X, Z\right]=1 ; \\
\operatorname{Cov}\left(v_{S, i s}, v_{S, j t} \mid X, Z\right)=\operatorname{Cov}\left(v_{L, i s}, v_{L, j t} \mid X, Z\right)=0 \text { if } i \neq j \text { or } s \neq t ; \\
\operatorname{Var}\left[u_{S, i} \mid X, Z\right]=\sigma_{S}^{2} ; \\
\operatorname{Var}\left[u_{L, i} \mid X, Z\right]=\sigma_{L}^{2} ; \\
\operatorname{Cov}\left[u_{S, j}, v_{S, i t} \mid X, Z\right]=\operatorname{Cov}\left[u_{L, j}, v_{L, i t} \mid X, Z\right]=0
\end{gathered}
$$

Where $i, j=1, \ldots, N$ and $s, t=1, \ldots, T$ in the above.

Furthermore, we assume:

$$
\begin{gathered}
\operatorname{Cov}\left[u_{S, i}, u_{L, i} \mid Z, X\right]=\sigma_{S L} ; i=1, \ldots, N ; \\
\operatorname{Cov}\left[v_{S, i t}, v_{L, i t} \mid Z, X\right]=\rho ; i=1, \ldots, N ; t=1, \ldots, T .
\end{gathered}
$$

The correlation between the individual effects $\left(\sigma_{S L}\right)$ incorporates the interactions that the reality of labour market outcome has with subjective wellbeing, which is influenced by immigrants' career goals. ${ }^{4} \rho$ accounts for 
the fact that some random factors are likely to affect immigrants' subjective wellbeing and labour market outcome simultaneously. For example, a more receptive host society and a economy with a lower unemployment rate are beneficial for immigrants in both subjective wellbeing and labour market attainment. In short, $\sigma_{S L}$ and

$$
\operatorname{Cov}\left[\varepsilon_{a, i s}, \varepsilon_{b, j t} \mid Z, X\right]= \begin{cases}1+\sigma_{S}^{2} & \text { for } i=j, s=t, a=b=S ; \\ \sigma_{S}^{2} & \text { for } i=j, s \neq t, a=b=S ; \\ 1+\sigma_{L}^{2} & \text { for } i=j, s=t, a=b=L ; \\ \sigma_{L}^{2} & \text { for } i=j, s \neq t, a=b=L ; \\ \sigma_{S L}+\rho & \text { for } i=j, s=t, a=S, b=L ; \\ \sigma_{S L} & \text { for } i=j, s \neq t, a=S, b=L ; \\ 0 & \text { for } i \neq j .\end{cases}
$$

The corresponding symmetric variance-covariance matrix with 5 waves of observations is:

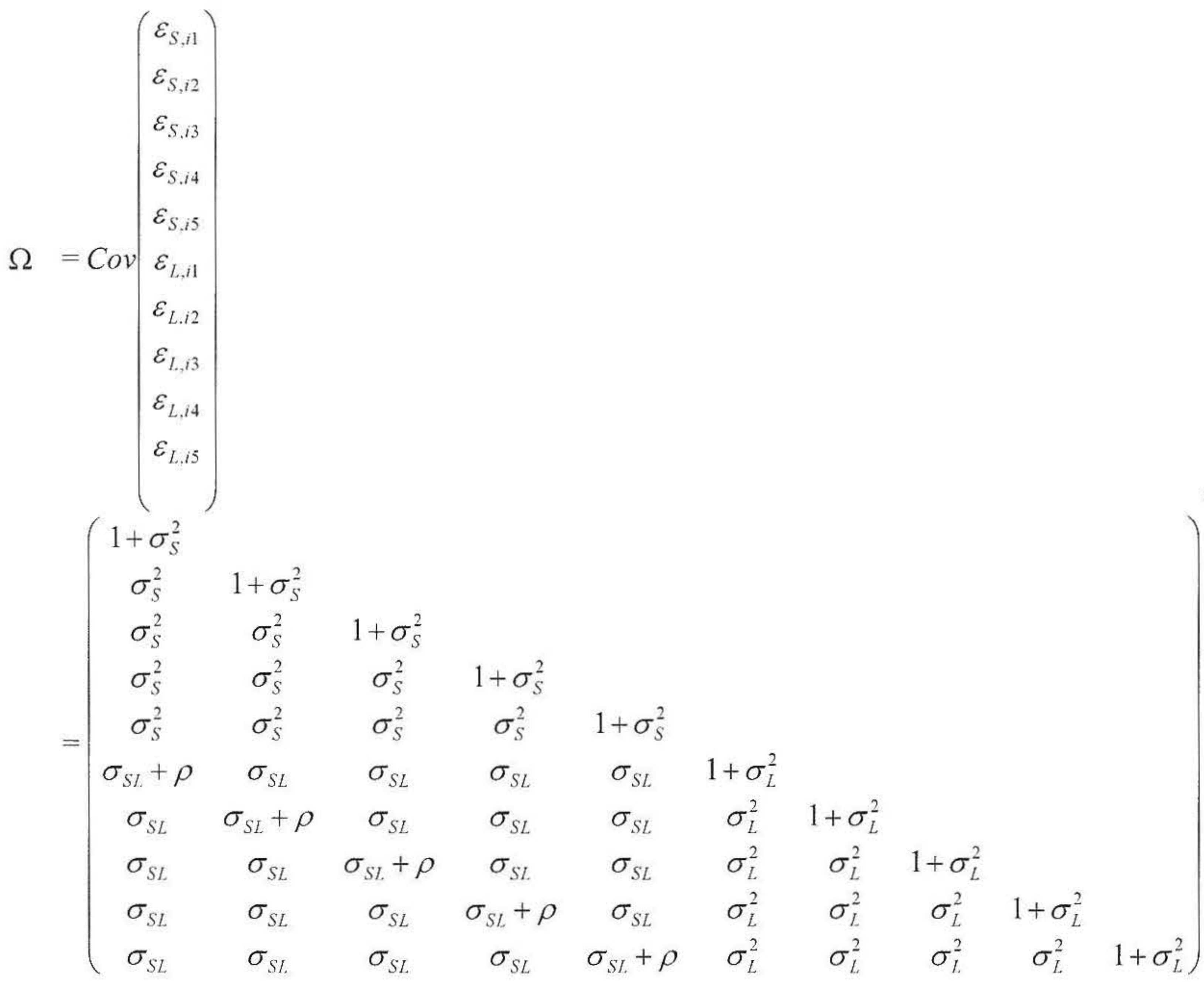


Within each time period, the joint distribution of subjective wellbeing and labour market outcomes as a cross-sectional term follows a bivariate normal distribution with correlation $\sigma_{S L}+\rho$. Thus, for observation $i$ at time $t$ (cross-sectional), when the actual subjective wellbeing level is $s$ and the labour market outcome is $l$, the joint probability is

$$
\begin{aligned}
L_{i t} & =\operatorname{Prob}\left(S_{i t}=s, L_{i t}=l\right) \\
& =\int_{L_{i t} B_{i t}} \phi_{2}\left(\varepsilon_{S . t i}, \varepsilon_{L, i t}, \sigma_{S L .}+\rho\right) d \varepsilon_{L, i t} d \varepsilon_{S, t t} \\
& s=0,1,2 ; l=0,1,2 .
\end{aligned}
$$

with $A_{i t}$ and $B_{i t}$ defined by the integration limits of the ordered probit model:

$$
\begin{gathered}
A_{i t}=\left\{\begin{array}{lr}
\left(-\infty,-\left(\beta^{\prime} Z_{i t}+\gamma_{1} L 1_{i t}+\gamma_{2} L 2_{i t}\right)\right] & \text { if } s_{i t}=0 \\
\left(-\left(\beta^{\prime} Z_{i t}+\gamma_{1} L 1_{i t}+\gamma_{2} L 2_{i t}\right), \mu_{S}-\left(\beta^{\prime} Z_{i t}+\gamma_{1} L 1_{i t}+\gamma_{2} L 2_{i t}\right)\right] & \text { if } s_{i t}=1 \\
\left(\mu_{S}-\left(\beta^{\prime} Z_{i t}+\gamma_{1} L 1_{i t}+\gamma_{2} L 2_{i t}\right), \infty\right) & \text { if } s_{i t}=2
\end{array}\right. \\
B_{i t}= \begin{cases}\left(-\infty,-\alpha^{\prime} X_{i t}\right] & \text { if } l_{i t}=0 \\
\left(-\alpha^{\prime} X_{i t}, \mu_{L}-\alpha X_{i t}\right] ; & \text { if } l_{i t}=1 \\
\left(\mu_{L}-\alpha X_{i t}, \infty\right) & \text { if } l_{i t}=2\end{cases}
\end{gathered}
$$

Because of the presence of common individual effects $\left(u_{S, i}, u_{L, i}\right)$ in subjective wellbeing and labour market outcome, respectively, $L_{i t}$ of individual $i$ are jointly normally distributed across time periods as well. As we jointly estimate the two equations as a panel model, the contribution of individual $i$ to the likelihood of the sample is a function of error terms across time and cross-section, which is a $2 T$ dimensional integral of normal distributed enror terms.

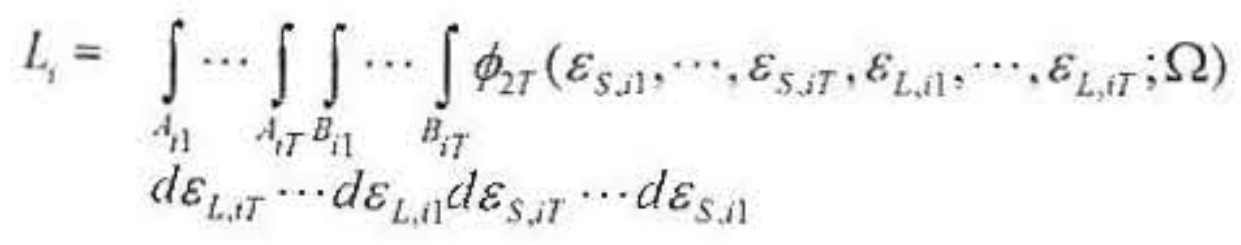

Where $\Omega$ is the $2 T \times 2 T$ variance-covariance matrix that describes the relations between subjective wellbeing and labour market outcome across $\mathrm{T}$ waves. When $\mathrm{T}=5$, $\Omega$ is defined by Equation 16 .

The parameters to be estimated are coefficients $\boldsymbol{\alpha}, \boldsymbol{\beta}$, cut-points $\mu_{S}$ and $\mu_{L}$, random effects $\sigma_{S}^{2}$ and $\sigma_{L}^{2}$, the covariance of individual effects $\sigma_{S L}$ and the correlation coefficient of the two stochastic error terms $\rho$. The identification of the above parameters $(\theta)$ is facilitated by: i) the nonlinearity of the model with normal distributions; ii) restrictions imposed on the variance-covariance structure as stated in Equations (7)--(14); iii) exclusion restrictions on the explanatory variables; for example, education and work experience are only included in the labour market outcomes equation. The log-likelihood function for the sample is then

$$
L_{N}(\theta)=\sum_{i=1}^{N} \ln \left(L_{i}\left(\theta ; Z_{i}, X_{i}\right)\right) .
$$

Evaluating $(2 \times T)$ dimensional integrals in the the above log-likelihood function directly (using numerical or analytical methods) is computationally intractable. Thus, the Geweke-Hajivassiliou-Keane (GHK) smooth recursive conditioning simulator, a simulated maximum likelihood procedure, ${ }^{5}$ is applied to estimate the parameters

$$
\widetilde{L}_{i}\left(\theta ; Z_{i}, X_{i}, \varepsilon_{S}, \varepsilon_{L}\right)=\frac{1}{R} \sum_{r=1}^{R} L_{i}\left(\theta ; Z_{i}, X_{i}, \xi_{S, r}, \xi_{L, r}\right)
$$

where $\mathrm{R}$ draws of truncated standard-normal-distributed sequences, $\xi_{S, r}$ and $\xi_{L, r}$, are generated (truncated functions are defined by $A_{i t}$ and $B_{i t}$ respectively). Hence the parameters are estimated by maximum log likelihood over the full sample

$$
\hat{\theta}=\underset{\theta}{\operatorname{argmax}} \sum_{i=1}^{N} \ln \left(\widetilde{L}_{i}\left(\theta ; Z_{i}, X_{i}, \varepsilon_{S}, \varepsilon_{L}\right)\right) .
$$

Estimating this systems equation model simultaneously using GHK, a full information maximum likelihood method, will yield consistent and efficient results. 


\section{Data and Variables}

In this study we utilise data from 1-5 waves of the Household, Income and Labour Dynamics in Australia (HILDA) Survey. The data are collected by a combination of face-to-face interview and self-completion questionnaire. The self-completion questionnaire has further reduction in the response rate in addition to the face-to-face interview. To avoid losing too many observations, we only use information from the face-to-face interview.

We focus our attention on the respondents of overseas born immigrants aged 25-55 at the time of the first interview and who are in the labour force for at least for two waves out of 5 waves in order to concentrate on their labour market attainment (for each individual, at least two observations are needed to capture the individual effect). By selecting the sample this way other than setting a fixed range, for example aged 25-60 for all the waves, we avoid individuals entering or leaving the sample as their ages hit the lower or upper bound. People aged over 60 are eligible for the aged pension and might behave differently. As for people under 25, many of them are still pursuing their education. Moreover, those who are studying towards a qualification might potentially do well in the labour market, but they select themselves out of labour force in favour of a better future career. Thus including those under 25 would potentially incur selectivity issue. Furthermore, we conduct the analysis separately for males and females. Gender differences in the division of household labour and labour market inequality are rooted in traditional gender norms and expectations, which might lead to gender differences in labour market performance and particularly in the relationship between job and life satisfaction. Simon (1995) reveals that employed wives are more likely relative to employed husbands to experience role conflicts, and feeling guilty from combining work and family. Also, Roxburgh (1996) finds that women are less successful than men with jobs involving heavier demands of personal energy, time and commitment, such as professional or managerial positions. As men and women undergo different work-family strains, we expect significant differences in the ways in which labour market events affect their life satisfaction. Finally, after the observations with missing values are removed from the sample, we obtain an estimation sample of 842 male migrants (with 3489 observations) and 753 female migrants (with 3024 observations). The number of observed individuals in a given year is determined by three factors. First, general panel attrition reduces the number of responses over time. Second, some individuals are out of the labour force in certain years. Third, missing values occur in certain waves. By adopting a unbalanced panel approach, the affect of attrition is reduced to the least in our study. ${ }^{6}$

\section{Subjective Wellbeing}

Psychologists recognise that the best method to gain information about a person's perspective on their life is to ask them directly. In our study, subjective wellbeing is measured by the answer to the question about overall life satisfaction: "All things considered, how satisfied are you with your life?". Ten choices are given ranging from 0 (totally dissatisfied) to 10 (totally satisfied). We group people with a life satisfaction score of 7-10 as Satisfied $(S=2), 5-6$ as Neutral $(S=1)$, and $0-4$ as Dissatisfied $(S=0)$.

Table 1: Job-life Relationship (pooled waves 1-5): Immigrants Entering HILDA Survey at Age of 25-55, by Country-of-origin and Gender

\begin{tabular}{lcccccccc}
\hline & \multicolumn{3}{c}{ Male } & \multicolumn{5}{c}{ Female } \\
\hline \multicolumn{1}{c}{} & Unemployed & Unskilled & Skilled & All & Unemployed & Unskilled & Skilled & All \\
\hline All & & & & & & & & \\
\%unhappy & 8.89 & 2.87 & 2.30 & 2.72 & 6.02 & 3.18 & 2.16 & 2.74 \\
\%neutral & 27.41 & 15.98 & 11.74 & 13.61 & 22.56 & 12.54 & 12.57 & 13.00 \\
\%happy & 63.70 & 81.15 & 85.97 & 83.66 & 71.43 & 84.28 & 85.27 & 84.26 \\
Observations & 135 & 1045 & 2309 & 3489 & 133 & 1228 & 1663 & 3024 \\
Western & & & & & & & & \\
\%unhappy & 7.02 & 2.68 & 2.08 & 2.38 & 6.12 & 1.55 & 1.66 & 1.75 \\
\%neutral & 29.82 & 11.09 & 10.67 & 11.33 & 26.53 & 10.17 & 10.84 & 11.07 \\
\%happy & 63.16 & 86.23 & 87.26 & 86.29 & 67.35 & 88.28 & 87.50 & 87.17 \\
Observations & 57 & 523 & 1397 & 1977 & 49 & 580 & 1024 & 1653 \\
non-Western & & & & & & & & \\
\%unhappy & 10.26 & 3.07 & 2.63 & 3.17 & 5.95 & 4.63 & 2.97 & 3.94 \\
\%neutral & 25.64 & 20.88 & 13.38 & 16.60 & 20.24 & 14.66 & 15.34 & 15.32 \\
\%happy & 64.10 & 76.05 & 83.99 & 80.22 & 73.81 & 80.71 & 81.69 & 80.74 \\
Observations & 78 & 522 & 912 & 1512 & 84 & 648 & 639 & 1371 \\
\hline
\end{tabular}


Traditionally, there are debates about the validity of interpersonal comparisons of subjective wellbeing, in that there are two forms of individual heterogeneity related to subjective wellbeing: heterogeneity in the utility function and heterogeneity in the expression function (Clark et al, 2005 ). The former is correlated with explanatory variables; and the later one is concerned with an individual's innate personality, which may play a major part both on how people actually feel and on how ready they are to reveal their feelings. Ignoring such individual heterogeneity may cause the estimator to be biased. On the assumption that individuals have similar utility functions, but at the same time that personal traits and the metric used by individuals are time-invariant, the panel model used in this study will adequately control for unobservable individual heterogeneity.

\section{Labour Market Outcomes}

Labour market outcomes $L$ is a discrete ordinal variable with $L=0$ for unemployed, $L=1$ for unskilled, and $L=2$ for skilled occupations. As for the reference group of the unemployed, they are likely to have the worst subjective wellbeing, which is not just due to the loss of income, but also the potential damage to one's identity in society and individual self-esteem. The hypothesis that unemployment leads to deterioration in an individual's wellbeing has been validated by researches using panel models (see Winkelmann \& Winkelmann, 1998; Clark et al, 2001 for Germany; and Clark, 2003 for the UK). For those employed and working on a specific occupation, skilled occupations more frequently emphasise conceptual skills, while unskilled occupations more frequently emphasise use of manual and verbal skills. Morse \& Weiss (1955) argue that each of the occupations shows quite a different pattern of satisfaction sources: working in a skilled job means having a purpose, gaining a sense of accomplishment; whilst working in a unskilled job is more about giving the individual a meaningful and socially integrating activity. Furthermore, occupations in different skill levels have different levels of prestige and social recognition, thus they provide different levels of sense of self-respect and self-worth. In this study, the categories of skilled occupations (skill level 1-3) and unskilled occupations (skill level 4-5) are defined in line with the second edition of the Australian Standard Classification of Occupation (ASCO 2). Thus, the skilled group includes the major groups of Managers, Professionals, Associate Professionals, Tradesmen and Advanced Clerks; the unskilled group includes Labourers, Operators, Elementary and Intermediate Clerks. By taking into account the quality of employment in the measure of labour market outcome, it is possible to test whether it is the fact of having a job per se, or the type of the job that is the key factor in promoting happiness.

The influence of income on individual's wellbeing is one of the most heavily researched topics in subjective wellbeing. However, using the same data source (HILDA wave 2) and controlling for individual characteristics, only a slight positive relationship between income and self-reported life satisfaction is found by Headey \& Wooden (2004), which is consistent with most European-based studies. This finding to some extent assures that the potential correlation between labour market attainment and life satisfaction mainly arises from non-financial factors. Income is not included in this study is also due to the fact that large number of missing value in income (in HILDA) will lead to further reduction in the sample size.

Table 1 tabulates labour force status against self-reported satisfaction using the pooled sample (waves 1--5). A positive relationship between labour market achievement and subjective wellbeing presents for male migrants. That is, the higher the occupational attainment, the more likely a male migrant is to be satisfied with his life, especially for the non-Western male migrants. For example, $1 \%$ more Western skilled workers and $7 \%$ more non-Western skilled workers are satisfied with their life relative to their unskilled counterparts. For female migrants, it seems that labour market achievement is quite irrelevant to their happiness based on these sample descriptive statistics.

\section{Explanatory Variables}

All variables are defined in the Appendix. Country-of-origin dummy is included in both labour market outcome and life satisfaction equations, along with age, immigration age and the cross-terms between them. Age and immigration age jointly define the immigrants' duration in Australia, ${ }^{7}$ which is a key variable for exploring the labour market and wellbeing assimilation processes. As found by Miller \& Neo (2003), the employability and earning of immigrants catch-up with those of their native-born counterparts as duration in Australia increases and the immigrants acquire Australian-specific skills. The cross-terms of age and immigration age with country-of-origin, respectively, enable the investigation of potential differential labour market and wellbeing adjustment process, as well as dynamic of job-life relationship between the Western and the non-Western migrants. In addition, dummies indicating English proficiency are included in both equations as English ability not only influences the transferability of human capital, but also is involved in every aspects of the immigrants' lives and defines their social circles.

As posited in the "bottom-up" theory in psychology, overall satisfaction with life is determined by satisfaction in different domains of life (Diener, 1984. Though the classification of life domains remains a subject of continuing research, wealth, family, health and work are of major importance (see the meta analysis, Cummins, 1996). In HILDA, wealth data is only available in wave 2 , and house ownership is used as a proxy for wealth. Thus, objective outcomes of work, housing, family and health other than subjective satisfactions in these domains, are included in the subjective wellbeing equation only. ${ }^{8}$ 
Table 2: Sample Statistics (Pooling Waves 1-5): Immigrants Entering HILDA Survey at Age of 25-55, by Country-of-origin and Gender

\begin{tabular}{|c|c|c|c|c|c|c|}
\hline & \multicolumn{3}{|c|}{ Male } & \multicolumn{3}{|c|}{ Female } \\
\hline & All & Western & non-Western & All & Western & non-Western \\
\hline Observations & 3489 & 1977 & 1512 & 3024 & 1653 & 1371 \\
\hline Individuals & 842 & 462 & 380 & 753 & 404 & 349 \\
\hline $\begin{array}{l}\text { Life satisfaction } \\
\text { Happy } \\
\text { Neutral } \\
\text { Unhappy }\end{array}$ & $\begin{array}{l}0.84 \\
0.14 \\
0.03\end{array}$ & $\begin{array}{l}0.86 \\
0.11 \\
0.02\end{array}$ & $\begin{array}{l}0.80 \\
0.17 \\
0.03\end{array}$ & $\begin{array}{l}0.84 \\
0.13 \\
0.03\end{array}$ & $\begin{array}{l}0.87 \\
0.11 \\
0.02\end{array}$ & $\begin{array}{l}0.81 \\
0.15 \\
0.04\end{array}$ \\
\hline $\begin{array}{l}\text { Labour market outcome } \\
\text { Skilled jobs } \\
\text { Unskilled jobs } \\
\text { Unemployed }\end{array}$ & $\begin{array}{l}0.66 \\
0.30 \\
0.04\end{array}$ & $\begin{array}{l}0.71 \\
0.26 \\
0.03\end{array}$ & $\begin{array}{l}0.60 \\
0.35 \\
0.05\end{array}$ & $\begin{array}{l}0.55 \\
0.41 \\
0.04\end{array}$ & $\begin{array}{l}0.62 \\
0.35 \\
0.03\end{array}$ & $\begin{array}{l}0.47 \\
0.47 \\
0.06\end{array}$ \\
\hline $\begin{array}{l}\text { Family structure } \\
\text { Married } \\
\text { De facto } \\
\text { Separated, divorced or widow } \\
\text { Single } \\
\text { Children } \\
\text { Without children } \\
\text { Children with couple } \\
\text { Sole parent }\end{array}$ & $\begin{array}{l}0.69 \\
0.12 \\
0.08 \\
0.11 \\
0.74 \\
0.26 \\
0.66 \\
0.08\end{array}$ & $\begin{array}{l}0.65 \\
0.16 \\
0.08 \\
0.11 \\
0.72 \\
0.28 \\
0.64 \\
0.08\end{array}$ & $\begin{array}{l}0.74 \\
0.06 \\
0.08 \\
0.12 \\
0.76 \\
0.24 \\
0.69 \\
0.07\end{array}$ & $\begin{array}{l}0.64 \\
0.13 \\
0.16 \\
0.08 \\
0.78 \\
0.22 \\
0.61 \\
0.16\end{array}$ & $\begin{array}{l}0.58 \\
0.17 \\
0.16 \\
0.09 \\
0.76 \\
0.24 \\
0.58 \\
0.17\end{array}$ & $\begin{array}{l}0.71 \\
0.07 \\
0.15 \\
0.06 \\
0.80 \\
0.20 \\
0.65 \\
0.15\end{array}$ \\
\hline $\begin{array}{l}\text { Other personal profile } \\
\text { Own housing } \\
\text { Long-term health conditions } \\
\text { AGE/10 } \\
\text { Immigration age / } 10 \\
\text { Native English speakers } \\
\text { English very well } \\
\text { English well } \\
\text { English bad }\end{array}$ & $\begin{array}{l}0.72 \\
0.15 \\
4.28 \\
2.04 \\
0.66 \\
0.20 \\
0.11 \\
0.03\end{array}$ & $\begin{array}{l}0.74 \\
0.16 \\
4.36 \\
1.90 \\
0.93 \\
0.06 \\
0.00 \\
0.00\end{array}$ & $\begin{array}{l}0.69 \\
0.12 \\
4.18 \\
2.22 \\
0.30 \\
0.38 \\
0.24 \\
0.08\end{array}$ & $\begin{array}{l}0.76 \\
0.12 \\
4.22 \\
1.88 \\
0.65 \\
0.22 \\
0.10 \\
0.03\end{array}$ & $\begin{array}{l}0.76 \\
0.13 \\
4.30 \\
1.66 \\
0.92 \\
0.07 \\
0.01 \\
0.00\end{array}$ & $\begin{array}{l}0.75 \\
0.10 \\
4.12 \\
2.14 \\
0.31 \\
0.41 \\
0.21 \\
0.06\end{array}$ \\
\hline $\begin{array}{l}\text { Human Capital Endowment } \\
\text { Australian tertiary education } \\
\text { Western tertiary education } \\
\text { non-Western tertiary education } \\
\text { Australian certificate } \\
\text { Western certificate } \\
\text { non-Western certificate } \\
\text { No post-secondary education } \\
\text { Work experience }\end{array}$ & $\begin{array}{l}0.18 \\
0.10 \\
0.07 \\
0.19 \\
0.11 \\
0.04 \\
0.30 \\
2.32 \\
\end{array}$ & $\begin{array}{l}0.17 \\
0.13 \\
0.00 \\
0.20 \\
0.19 \\
0.00 \\
0.30 \\
2.47\end{array}$ & $\begin{array}{l}0.20 \\
0.05 \\
0.16 \\
0.19 \\
0.00 \\
0.10 \\
0.30 \\
2.12\end{array}$ & $\begin{array}{l}0.20 \\
0.07 \\
0.09 \\
0.18 \\
0.06 \\
0.03 \\
0.38 \\
1.98\end{array}$ & $\begin{array}{l}0.23 \\
0.11 \\
0.00 \\
0.21 \\
0.10 \\
0.00 \\
0.36 \\
2.10 \\
\end{array}$ & $\begin{array}{l}0.17 \\
0.02 \\
0.21 \\
0.14 \\
0.01 \\
0.06 \\
0.40 \\
1.83 \\
\end{array}$ \\
\hline
\end{tabular}

Human capital variables (education and work experience) are included in the labour market outcome equation only, which provides the exclusion restrictions that enhances the identification of the simultaneous equation model, even though restrictions in the variance-covariance structure already provide sufficient identification conditions. Although education is widely used as an explanatory variable for subjective wellbeing, the view that education may be only indirectly related to wellbeing through occupation is supported by Witter et al (1984). Their analysis shows that, when occupation status is controlled for, the correlation between education and subjective wellbeing in the United States drops from 0.13 to 0.06 .
Using first wave of HILDA, Shields et al (2007) find a negative relationship, and they ascribed it to the notion that well-educated people normally have higher life expectations. This statement is actually describing the indirect effect of education on subjective wellbeing. In this model, education contributes to life satisfaction indirectly through the interactions of a person's labour market reality and his/her life satisfaction, which is captured by the correlation between them. As for women, especially for single mothers, having children may have a great impact on their career paths. Therefore, the dummies of whether having children and being a single mother are added to the female labour market outcome equation as well. 
As shown in Table 1, regardless of gender, Western migrants are more satisfied with their lives relative to their non-Western counterparts. At the same time, though non-Western migrants are better educated (about 10\% more likely have a tertiary degree), both non-Western male and female migrants perform worse in the Australian labour market than their Western counterparts. For example, compared to their western counterparts, $11 \%$ less non-Western male migrants and $16 \%$ less non-Western female migrants are working in a skilled job while $2 \%$ more non-Western male migrants and $3 \%$ more non-Western female migrants are unemployed. In addition, compared to Western migrants, about $9 \%$ and $13 \%$ (male and female, respectively) more non-Western migrants are legally married; $10 \%$ less of them are in a de facto relationship; $4 \%$ more of them have children; $1 \%$ and $2 \%$ (male and female, respectively) less of them are sole parents. They are also less likely to be a house owner, and $3 \%$ and $4 \%$ (male and female, respectively) less of them have long-term health conditions (Table 1).

\section{Results}

Does Labour Market Achievement Matter? By examining the role that labour market achievement plays in immigrants' subjective wellbeing, we can shed some light on their migration incentive. Different conceptual structures for the job-life relationship are implied in the bivariate and univariate models, and the estimated results of both are reported in Table 2 . In the bivariate models, the impact of labour market achievement on one's subjective wellbeing comes from two sources. One is the direct benefits of having a job (skilled or unskilled), which is indicated by the estimated coefficients of the labour market outcomes in the subjective wellbeing equation. The other is the job-life interaction that result from unobserved common factors. In the univariate models, labour market outcomes are treated as independent of life satisfaction, and can not separate these two different sources of effects.

Gruenberg (1980) argues that work directly contributes to subjective wellbeing by providing extrinsic returns (pay, job security and the like) and intrinsic rewards (for example. self-realisation from work). He also suggests that the former dominates for unskilled workers, and the later for skilled workers. However, different from extrinsic returns from a job, the intrinsic rewards are more likely to be influenced by individuals' career goals and thus are individual specific. The estimates for $\sigma_{S}^{2}$ and $\sigma_{L}^{2}$, the variances of time-invariant error components in the subjective wellbeing and labour market outcome equations by both univariate and bivariate models, are strongly significant and very large in magnitude, which suggests that unobservable individual traits are important in determining one's occupational achievement and views about life. However, the importance of occupational achievement on life satisfaction is also individual specific, and this is only be accounted for in the bivariate model by the cross-equation correlations $\left(\sigma_{W L}\right.$ and $\rho$ ). As shown in Table 2, they are both positive and highly significant (at 0.01 level) in both male and female models, which suggests that the univariate model is inconsistent as it ignores the endogeneity of labour market outcomes in the subjective wellbeing equation. The individual specific effects, both $\sigma_{S}^{2}$ and $\sigma_{L}^{2}$ in the bivariate model are smaller in magnitude relative to those for the univariate models, presumably, due to the fact that the correlations between labour market outcome and subjective wellbeing have captured part of the unobserved effects. Thus, in the bivariate model, the positive correlation covariances $\left(\sigma_{S L}=0.283\right.$ for male and $\sigma_{S L}=0.461$ for female) of the time-invariant error components implies that unobserved personal traits that drive one succeed in the labour market might also make job a greater contributor to one's happiness. For example, compared to those whose central life interest is not career related, individuals with career ambitions are more likely to do well in the labour market, also their labour market achievement has a heavier weight in their life satisfaction. For them, the realisation of career goals will boost life satisfaction significantly: inversely, goals can be detrimental to life satisfaction when goal strivings in the labour market are not rewarded. At the same time, the positive coefficient correlations ( $\rho=0.241$ for male and $\rho=0.311$ for female) of the idiosyncratic error terms implies that socio-economic environment that is independent of individuals tends to affect immigrants labour market outcome and subjective wellbeing in the same direction.

Treating labour market outcomes as exogenous, the univariate models suggest that having a job, especially a skilled job, boosts male immigrants' life satisfaction, while having no effect on their female counterparts. After the endogenous relationship between labour market outcomes and life satisfaction are accounted for in the bivariate models, direct benefits from employment and better occupation, as showed by the estimated coefficients of the two dummy variables in the labour market outcomes equation, seem to have no significant effect on male immigrants' subjective wellbeing, and the stress from work. especially skilled jobs, actually undermines the wellbeing of female migrants.

In the bivariate models, the total (direct and indirect) impact of immigrants' labour market attainment on subjective wellbeing is represented as treatment effects. As elaborated in Table 2, the treatment effects are calculated as the difference of probabilities of being satisfied about life conditional on particular labour market outcome versus on the reference group. Eventually, compared to the univariate models, the predictions from the bivariate system imply a greater impact of labour market achievement on subjective wellbeing. For example, it is predicted by the bivariate model that males (females) working in a skilled job compared to being unemployed, are $16.54 \%(5.31 \%)$ more 
likely to feel satisfied about life, compared to a lower

labour market achievement exogenously. $12.64 \%(1.65 \%)$ predicted by the univariate model treating

Table 3: Job-life Relationship: Direct, Indirect and Total Effects

\begin{tabular}{|c|c|c|c|c|}
\hline & \multicolumn{2}{|c|}{ Male } & \multicolumn{2}{|c|}{ Female } \\
\hline & Bivariate & Univariate & Bivariate & Univariate \\
\hline \multicolumn{5}{|c|}{ Estimated Coefficients in Subjective Wellbeing Equation } \\
\hline Skilled Job & $\begin{array}{l}-0.104 \\
(0.350)\end{array}$ & $\begin{array}{c}0.736^{* * *} \\
(0.173)\end{array}$ & $\begin{array}{l}-1.047^{* * *} \\
(0.327)\end{array}$ & $\begin{array}{l}0.130 \\
0.197)\end{array}$ \\
\hline Unskilled Job & $\begin{array}{c}0.210 \\
(0.242)\end{array}$ & $\begin{array}{c}0.559 * * * \\
(0.174)\end{array}$ & $\begin{array}{c}-0.383^{*} \\
(0.240)\end{array}$ & $\begin{array}{c}0.138 \\
(0.197)\end{array}$ \\
\hline \multicolumn{5}{|l|}{ Variance-covariance Parameters } \\
\hline$\sigma_{s}^{2}$ & $1.253 * * *$ & $1.451^{* * *}$ & $1.319 * * *$ & $1.532 * * *$ \\
\hline$\sigma_{t}^{2}$ & $\begin{array}{c}(0.152) \\
1.768^{* * *} \\
(0.216)\end{array}$ & $\begin{array}{c}(0.032) \\
2.215^{* * *} \\
(0.022)\end{array}$ & $\begin{array}{c}(0.192) \\
1.766 * * * \\
(0.230)\end{array}$ & $\begin{array}{c}(0.033) \\
2.333 * * * \\
(0.018)\end{array}$ \\
\hline$\sigma_{s L}$ & $\begin{array}{c}0.283^{* * *} \\
(0.105)\end{array}$ & -- & $\begin{array}{c}0.461^{* * *} \\
(0.104)\end{array}$ & -- \\
\hline$\rho$ & $\begin{array}{c}0.241^{* * *} \\
(0.093)\end{array}$ & -- & $\begin{array}{c}0.311^{* * *} \\
(0.088)\end{array}$ & -- \\
\hline \multicolumn{5}{|c|}{ Treatment (Bivariate)/Marginal (Univariate) Effects } \\
\hline Satisfied| Unskilled vs. Unemployed & $0.1317^{* * *}$ & $0.1047^{* * *}$ & 0.0493 & 0.0175 \\
\hline $\mathrm{P}(\mathrm{S}=2 \mid \mathrm{L}=1)-\mathrm{P}(\mathrm{S}=2 \mid \mathrm{L}=0)$ & $(0.043)$ & $(0.0395)$ & $(0.0361)$ & $(0.0266)$ \\
\hline Satisfied|Skilled vs. Unemployed & $0.1654^{* * *}$ & $0.1264 * * *$ & 0.0531 & 0.0165 \\
\hline $\mathrm{P}(\mathrm{S}=2 \mid \mathrm{L}=2)-\mathrm{P}(\mathrm{S}=2 \mid \mathrm{L}=0)$ & $(0.0437)$ & $(0.0395)$ & $(0.0379)$ & $(0.0266)$ \\
\hline Satisfied |Skilled vs. Unskilled & $0.0337 * *$ & $0.0217^{*}$ & 0.0038 & -0.0010 \\
\hline $\mathrm{P}(\mathrm{S}=2 \mid \mathrm{L}=2)-\mathrm{P}(\mathrm{S}=2 \mid \mathrm{L}=1)$ & $(0.016)$ & $(0.0129)$ & $(0.0159)$ & $(0.0122)$ \\
\hline
\end{tabular}

***, **and * indicate significant level of $1 \%, 5 \%$ and $10 \%$ respectively, and standard errors are in parentheses;

In summary, a univariate approach ignoring the cross-equation correlation would under-estimate the magnitude of job-life relationship for males. Also, it can not separate the direct (benefit from work) and indirect (the interaction between work and life satisfaction that is influenced by individual's career goals) effects on the job-life relationship. The bivariate approach that accounts for the endogeneity in the job-life relationship proves that the indirect effect plays an more significant role in males' job-life relationship. For females, neither the univariate approach nor the treatment effect from a bivariate approach suggests a significant effect of labour market achievement on subjective wellbeing. However, the bivariate model detects that, working in skilled jobs significantly reduces a woman's self-perceived wellbeing (based on the direct effect of work indicated by the estimated coefficients). This effect is somehow blurred, because the total job-life relationship is dominated by the indirect and endogenous interaction between labour market outcomes and life satisfaction that is also found in their male counterparts.

\section{Male Immigrants: Who has Job Concerns?}

As known above, labour market achievement plays an important role in male immigrants' subjective wellbeing. By simultaneously estimating a bivariate system, we can further identify for whom job has a heavier weight in their life satisfaction based on the marginal effects of the explanatory variables on the treatment effects, such as the treatment effects of having a skilled job versus being unemployed. The marginal effects on labour market outcome (skilled job) and subjective wellbeing (satisfied) are also reported to provide further insight. ${ }^{10}$ Based on the marginal effects in Table 3, we find that a job has greater impacts on the life for two types of male immigrant: i) those who are superior to the others in terms of human capital, and are supposed to have higher labour market achievement; ii) those whose subjective wellbeing is undermined by their disadvantages in other life domains, thus improvement in employment is much needed to boost their life satisfaction. Individuals under the above situations are likely to have higher expectation for employment. As informed by the 
previous analysis, male immigrants' job-life relationship is

career expectations and the labour market reality.

likely to be dominated by the discrepancies between their

Table 4: Average Marginal Effects on the Labour Market Outcomes, Wellbeing and Job-life Relationship

\begin{tabular}{|c|c|c|c|c|c|c|}
\hline & \multicolumn{3}{|c|}{ Male } & \multicolumn{3}{|c|}{ Female } \\
\hline & $\begin{array}{l}\text { Skilled } \\
\text { Job }\end{array}$ & Satisfied & $\begin{array}{c}\text { Skilled } \\
\text { vs. } \\
\text { Unemployed }\end{array}$ & $\begin{array}{l}\text { Skilled } \\
\text { Job }\end{array}$ & Satisfied & $\begin{array}{c}\text { Skilled } \\
\text { vs. } \\
\text { Unemployed }\end{array}$ \\
\hline Own Housing & & $\begin{array}{c}0.0446 * * * \\
(0.0175)\end{array}$ & $\begin{array}{c}-0.0218^{* * *} \\
(0.0096)\end{array}$ & & $\begin{array}{c}0.0534^{* * * *} \\
(0.0189)\end{array}$ & $\begin{array}{l}-0.0075 \\
(0.0073)\end{array}$ \\
\hline Long-term Health Conditions & & $\begin{array}{l}-0.0230 \\
(0.0174)\end{array}$ & $\begin{array}{l}0.0115 \\
(0.0084)\end{array}$ & & $\begin{array}{c}-0.0538 * * * \\
(0.0214)\end{array}$ & $\begin{array}{c}0.0084 \\
(0.0077)\end{array}$ \\
\hline Sole Parent & & $\begin{array}{l}-0.1339 * * \\
(0.0663)\end{array}$ & $\begin{array}{c}0.0344 * * * \\
(0.0131)\end{array}$ & & $\begin{array}{l}0.0565^{*} \\
(0.0352)\end{array}$ & $\begin{array}{l}-0.0135 \\
(0.0127)\end{array}$ \\
\hline De Facto without Children & & $\begin{array}{l}0.0213 \\
(0.0357)\end{array}$ & $\begin{array}{l}-0.0091 \\
(0.0153)\end{array}$ & & $\begin{array}{c}0.0115 \\
(0.0396)\end{array}$ & $\begin{array}{l}-0.0019 \\
(0.0070)\end{array}$ \\
\hline De Facto with Children & & $\begin{array}{l}-0.0044 \\
(0.0363)\end{array}$ & $\begin{array}{c}0.0017 \\
(0.0143)\end{array}$ & & $\begin{array}{l}-0.0788^{*} \\
(0.0430)\end{array}$ & $\begin{array}{c}0.0092 \\
(0.0114)\end{array}$ \\
\hline Married without Children & & $\begin{array}{l}0.0872 * * * \\
(0.0295)\end{array}$ & $\begin{array}{l}-0.0456 * * * \\
(0.0158)\end{array}$ & & $\begin{array}{r}0.0734 * * \\
(0.0354)\end{array}$ & $\begin{array}{l}-0.0143 \\
(0.0156)\end{array}$ \\
\hline Married with Children & & $\begin{array}{l}0.0679 * * \\
(0.0303)\end{array}$ & $\begin{array}{l}-0.0334 * * * \\
(0.0137)\end{array}$ & & $\begin{array}{c}0.0123 \\
(0.0358)\end{array}$ & $\begin{array}{l}-0.0033 \\
(0.0064)\end{array}$ \\
\hline $\begin{array}{l}\text { Separated, Divorced or Widow } \\
\text { without Children }\end{array}$ & & 0.0130 & -0.0054 & & $-0.1855^{* * *}$ & 0.0204 \\
\hline $\begin{array}{l}\text { Separated, Divorced or Widow } \\
\text { with Children }\end{array}$ & & $\begin{array}{c}(0.0492) \\
-0.1170^{* *}\end{array}$ & $\begin{array}{l}(0.0209) \\
0.0319^{* *}\end{array}$ & & $\begin{array}{l}(0.0675) \\
-0.0877^{* *}\end{array}$ & $\begin{array}{c}(0.0185) \\
0.0061\end{array}$ \\
\hline & & $(0.0484)$ & $(0.0136)$ & & $(0.0439)$ & $(0.0117)$ \\
\hline Non-western & $\begin{array}{c}-0.0653^{* *} \\
(0.0307)\end{array}$ & $\begin{array}{c}-0.0473^{* *} \\
(0.0208)\end{array}$ & $\begin{array}{c}0.0060 \\
(0.0166)\end{array}$ & $\begin{array}{c}-0.0673^{* *} \\
(0.0290)\end{array}$ & $\begin{array}{l}-0.0279 \\
(0.0220)\end{array}$ & $\begin{array}{l}-0.0118 \\
(0.0105)\end{array}$ \\
\hline English Very Well & $\begin{array}{c}0.0658^{* * *} \\
(0.0229)\end{array}$ & $\begin{array}{l}-0.0026 \\
(0.0199)\end{array}$ & $\begin{array}{c}0.0081 \\
(0.0106)\end{array}$ & $\begin{array}{c}0.0150 \\
(0.0237)\end{array}$ & $\begin{array}{l}-0.0331^{*} \\
(0.0205)\end{array}$ & $\begin{array}{l}0.0046 \\
(0.0061)\end{array}$ \\
\hline English Well & $\begin{array}{c}0.0081 \\
(0.0310)\end{array}$ & $\begin{array}{c}-0.0475^{*} \\
(0.0290)\end{array}$ & $\begin{array}{l}0.0228^{*} \\
(0.0128)\end{array}$ & $\begin{array}{c}-0.0482 \\
(0.0364)\end{array}$ & $\begin{array}{c}-0.1209 * * * \\
(0.0332)\end{array}$ & $\begin{array}{c}0.0072 \\
(0.0151)\end{array}$ \\
\hline English Bad & $\begin{array}{c}0.0122 \\
(0.0438)\end{array}$ & $\begin{array}{l}-0.0725^{*} \\
(0.0501)\end{array}$ & $\begin{array}{c}0.0326^{*} \\
(0.0183)\end{array}$ & $\begin{array}{l}-0.1305^{*} \\
(0.0702)\end{array}$ & $\begin{array}{l}-0.0916^{*} \\
(0.0524)\end{array}$ & $\begin{array}{c}-0.0002 \\
(0.0123)\end{array}$ \\
\hline Non-western Certificate & $\begin{array}{c}0.0668 \\
(0.0707)\end{array}$ & $\begin{array}{c}-0.0020 \\
(0.0034)\end{array}$ & $\begin{array}{c}0.0056 \\
(0.0062)\end{array}$ & $\begin{array}{c}0.0697 \\
(0.0738)\end{array}$ & $\begin{array}{c}-0.0081 \\
(0.0089)\end{array}$ & $\begin{array}{c}0.0040 \\
(0.0049)\end{array}$ \\
\hline Western Certificate & $\begin{array}{c}0.1853 * * * \\
(0.0474)\end{array}$ & $\begin{array}{c}-0.0063 \\
(0.0073)\end{array}$ & $\begin{array}{c}0.0173^{* * *} \\
(0.0071)\end{array}$ & $\begin{array}{c}0.2878 * * * \\
(0.0566)\end{array}$ & $\begin{array}{c}-0.0341 * * * \\
(0.0112)\end{array}$ & $\begin{array}{c}0.0234 * * \\
(0.0108)\end{array}$ \\
\hline Australian Certificate & $\begin{array}{c}0.1573 * * * \\
(0.0313)\end{array}$ & $\begin{array}{l}-0.0052 \\
(0.0062)\end{array}$ & $\begin{array}{c}0.0143^{* * *} \\
(0.0053)\end{array}$ & $\begin{array}{c}0.1203 * * * \\
(0.0284)\end{array}$ & $\begin{array}{c}-0.0140 * * * \\
(0.0046)\end{array}$ & $\begin{array}{l}0.0075^{*} \\
(0.0039)\end{array}$ \\
\hline Non-western Tertiary Education & $\begin{array}{c}0.2655^{* * *} \\
(0.0498)\end{array}$ & $\begin{array}{l}-0.0097 \\
(0.0100)\end{array}$ & $\begin{array}{c}0.0274 * * * \\
(0.0099)\end{array}$ & $\begin{array}{c}0.1989 * * * \\
(0.0459)\end{array}$ & $\begin{array}{c}-0.0233 * * * \\
(0.0081)\end{array}$ & $\begin{array}{l}0.0139 * * \\
(0.0070)\end{array}$ \\
\hline Western Tertiary Education & $\begin{array}{c}0.4562 * * * \\
(0.0294)\end{array}$ & $\begin{array}{c}-0.0196 \\
(0.0173)\end{array}$ & $\begin{array}{c}0.0715^{* * *} * \\
(0.0229)\end{array}$ & $\begin{array}{c}0.4584 * * * \\
(0.0356)\end{array}$ & $\begin{array}{c}-0.0562 * * * \\
(0.0153)\end{array}$ & $\begin{array}{c}0.0553 * * * \\
(0.0191)\end{array}$ \\
\hline Australian Tertiary Education & $\begin{array}{c}0.4201^{* * *} \\
(0.0276)\end{array}$ & $\begin{array}{l}-0.0175 \\
(0.0158)\end{array}$ & $\begin{array}{c}0.0586 * * * \\
(0.0181)\end{array}$ & $\begin{array}{c}0.4508^{* * *} \\
(0.0250)\end{array}$ & $\begin{array}{c}-0.0551^{* * *} \\
(0.0145)\end{array}$ & $\begin{array}{c}0.0531 * * * \\
(0.0178)\end{array}$ \\
\hline Working Experience & $\begin{array}{c}0.4986 * * * \\
(0.0191)\end{array}$ & $\begin{array}{l}-0.0217 \\
(0.0181)\end{array}$ & $\begin{array}{c}0.0520 * * * \\
(0.0196)\end{array}$ & $\begin{array}{c}0.4698^{* * *} \\
(0.0193)\end{array}$ & $\begin{array}{c}-0.0191 \\
(0.0228)\end{array}$ & $\begin{array}{c}0.0655^{* * *} * \\
(0.0236)\end{array}$ \\
\hline $\begin{array}{l}\text { Sole parent } \\
\text { Children with couple }\end{array}$ & & & & $\begin{array}{c}-0.0630^{*} \\
(0.0358) \\
-0.0186 \\
(0.0287)\end{array}$ & & \\
\hline
\end{tabular}

***, **and * indicate significant level of $1 \%, 5 \%$ and $10 \%$ respectively, and standard errors are in parentheses. 
Male migrants with higher level of education and longer working experience are potentially more successful in the labour market. Thus, they might have higher career expectations, and employment issues tend to carry heavier weight in their subjective wellbeing. Because human capital variables are not included in subjective wellbeing equation, this effect is indirectly generated by the interactions between labour market outcomes and subjective wellbeing. In addition, we find that qualifications acquired from different source countries are not equally rewarded, Western qualifications are more highly regarded than Australian qualifications, while non-Western qualifications are treated far from equivalent to the same level of western and Australian qualifications. This is consistent with the findings of Hawthorne (1997). In Table 3, as shown by the marginal effects on the highest labour market attainment (working on a skilled job), compared to male immigrants with local tertiary education, those with Western tertiary education are $3.61 \%$ more likely to be offered a skilled job, whilst those with non-Western tertiary education are $15.46 \%$ less likely to be in a skilled job. When associating the above findings in labour market achievement with those in job-life relationship, as demonstrated by the marginal effects on treatment effect of working in a skilled job in contrast to being unemployed, we find that indeed male immigrants who are supposed to do well in the labour market are more concerned about their employment and the quality of their job. Specifically, in the case of losing a skill job, compared to male migrants without any post secondary education, those with Australian (Western) degrees are 7.15\% (5.86\%) more likely to suffer deterioration in life satisfaction, while it is a much less $2.74 \%$ for those with non-Western degrees.

For male immigrants who confront difficulties in other life domains, they might have higher desire to improve their life via employment. Thus labour market outcomes play a more important role in their life satisfaction. As demonstrated by the marginal effects on being satisfied and on treatment effect of working in a skilled job in contrast to being unemployed (Table 3 ), i) owning property is an important symbol of settling-down and establishment a new life in Australia, male migrants without home ownership are $4.46 \%$ less satisfied about their life. If being offered a skilled job, they are likely to be $2.18 \%$ happier than one owns his home. ii) Owing to the financial stress and social responsibility related to being a sole-parent, single fathers are $13.4 \%$ less happy than their no-child counterparts. They are more vulnerable to job loss as well; losing a skilled job is likely to cost them a $3.44 \%$ more reduction in life satisfaction. iii) Although English ability does not have a significant negative on male migrants' labour market outcome, poor English proficiency might have hindered their subjective wellbeing by constraining their access to public service and community activities. As shown in Table 3. male migrants with poor English are $7.25 \%$ less likely to be happy compared to their native English speaking counterparts. Therefore, the social contact related to having a job is more highly valuable for those with poor English proficiency, and losing a skilled job is likely to lead to a $3.26 \%$ higher level of deterioration in their life satisfaction compared to the male native English speakers.

\section{Are Female Immigrants Different?}

As known from the previous analysis, stress from work has a directly deleterious effect on female immigrants' life satisfaction, in particular, a skilled job is more stressful than a unskilled job. This is consistent with the finding in Long's 2005 study on gender differences in job satisfaction in Australia using HILDA wave $1 .{ }^{11}$ However, the interactions between labour market outcome and life satisfaction also play an important role in the female immigrants' job-life relationship. Depending on individual specific job attitudes, labour market achievement carries heavier weight on the subjective wellbeing of female immigrants who have a career goal in mind, while it can be trivial for the wellbeing of those whose center-life-interest is family. As shown in Table 3, the impact of labour market achievement on life satisfaction is only significant for well-educated female immigrants. This suggests that the well-educated female immigrants are likely maintaining their career ambitions. Compared to those without post-secondary education, female immigrants with Western (non-Western) tertiary education are $45.8 \%$ (19.9\%) more likely to be working on a skilled job. Meanwhile, they are $5.53 \%(1.39 \%)$ more likely to value a skilled position. However, presumably facing the challenge of balancing the job-home roles, ${ }^{12}$ they are $5.62 \%(2.33 \%)$ less likely to be satisfied with life. Usually, skilled jobs held by educated female immigrants normally demand more personal energy, time and commitment relative to a unskilled job. At the same time, females spend more time in child care and home duties than their spouses (Berk \& Berk, 1978; Gutek et al, 1981; and Barnett \& Marshall, 1991). It makes things worse that, being immigrants, it is difficult for them to get help with child care from other members of their family. For other female immigrants, their career aspirations may have been suppressed by household duty, and work may not be their central life interest. For example, compared to no-child single women, single mothers are $6.3 \%$ less likely to be working on a skilled position, but they are $5.65 \%$ more likely to be happy. Another example is non-Western female immigrants. Given that interpersonal skills usually are a basic requirement for female-dominated positions, non-Western females may have encountered great cultural obstacles in the labour market. With duration in Australia, non-Western females make less progress in the labour market relative to their Western counterparts, however, they have a much greater gain in life satisfaction (Figure 2).

\section{Does Culture Matter?}

After controlling for human capital endowments in the labour market outcome equation and other major life domains in the subjective wellbeing equation, in this section, we investigate how country-of-origin background affects 
immigrants' labour market and wellbeing assimilation processes, as well as the evolvement of the job-life relationship by focusing on male immigrants only.

In general, the labour market performance and subjective wellbeing of the non-Western migrants appears to be inferior to that of their Western counterparts. As shown in Table 3, non-Western male migrants are $6.53 \%$ less likely to hold a skilled job, and $4.73 \%$ less likely to feel satisfied about life relative to their Western counterparts. Nevertheless, this disparity evolves with age and duration in Australia, and it is also affected by immigration age. The two continuous variables age and immigration age jointly decide immigrants' duration in Australia (Age Immigration age). Thus, we fix the gaps between age and immigration age to 5, 20 and 35 respectively, which represent durations of 5,20 and 35 years in Australia post migration, and predict the probabilities within the age range. Based on these predicted values, Figures 1 and 2 are drawn. These figures reflect the age patterns and duration effects on male/female immigrants' labour market outcomes, life satisfaction and job-life relationship, respectively. The following analysis investigates disparities between Western and non-Western in the above areas. The Western migrants share the same cultural heritage and social structure with mainstream Australians. Thus the Western migrants with 35 years of duration in Australia are expected to be very similar to the native Australians, and can be regarded as the reference group.

Figure 1: Country-of-origin Disparities in Job, Wellbeing and Job-life Relationship
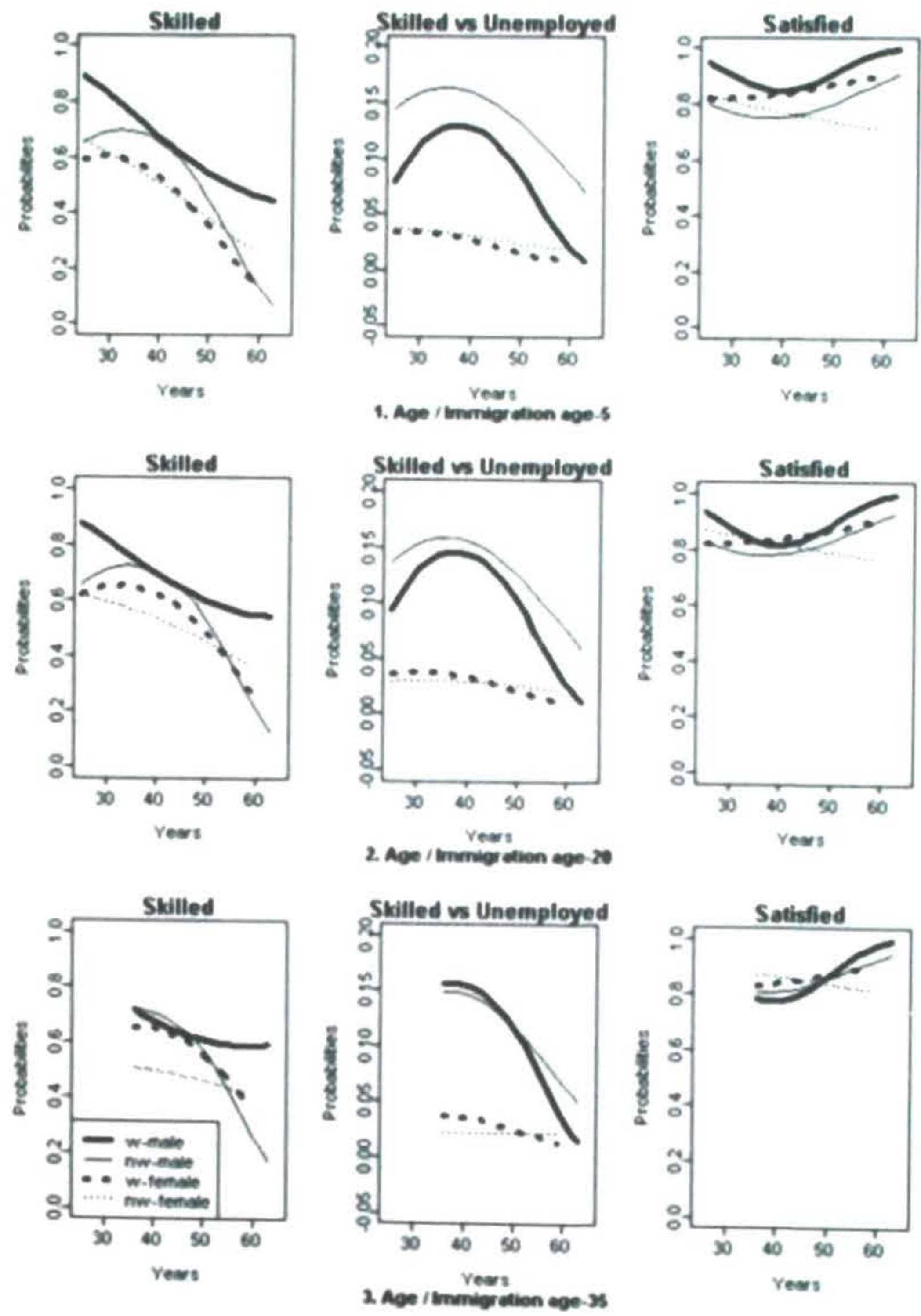
As shown in Figure 2, in the labour market, male immigrants with longer duration in Australia do better regardless of their culture backgrounds. Indeed, immigrants who stay longer in Australia may have established better cultural knowledge and social networks, which help them reach their career goals. Duration in Australia is especially important for the non-Western males, and they make greater progress in the labour market and catch up with their Western counterparts over time. Moreover, among the older immigrants, those who migrated at a younger age are likely to do much better, because the later they migrate, the more social capital in their home country is forgone, and the harder for them to transfer their home country human capital into Australian labour market.
However, the Western and the non-Western show a contrasting picture in terms of wellbeing adjustment and job-life relationship evolvement. The recent mid-aged male Western migrants enjoy higher life satisfaction than their long-term-migrated counterparts, despite their doing worse in the labour market. It could be the case that normally more active and capable men would tend to explore the possibility of establishing a new life in a new country, and these more adventurous people are more likely to be optimistic about life as well. The finding also suggest that their initiate migration motivation are likely to be a better lifestyle rather than career development. Indeed, as shown in Figure 2, work play a less important role in their life satisfaction compared to their long-term-migrated counterparts.

Figure 2: Duration Effects on Job, Wellbeing and Job-life Relationship
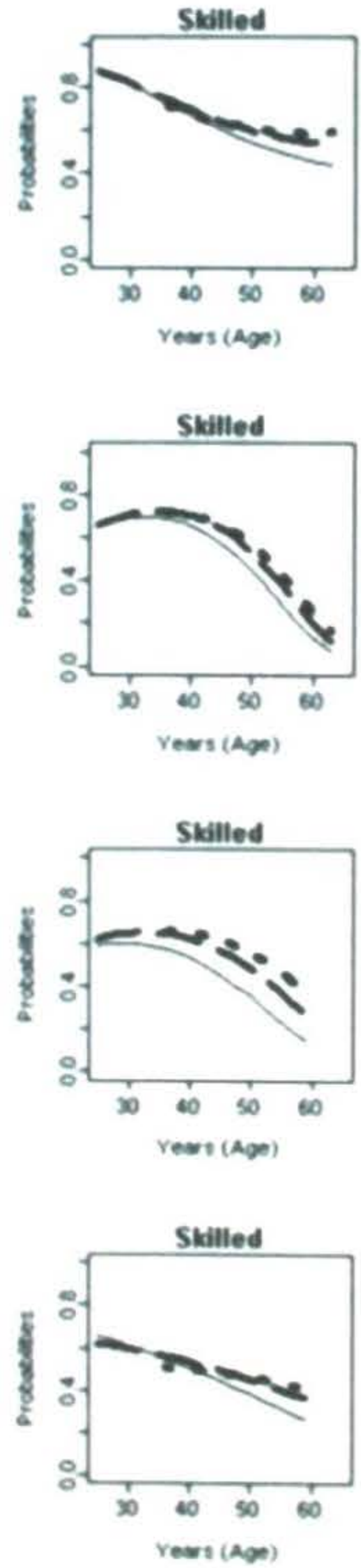
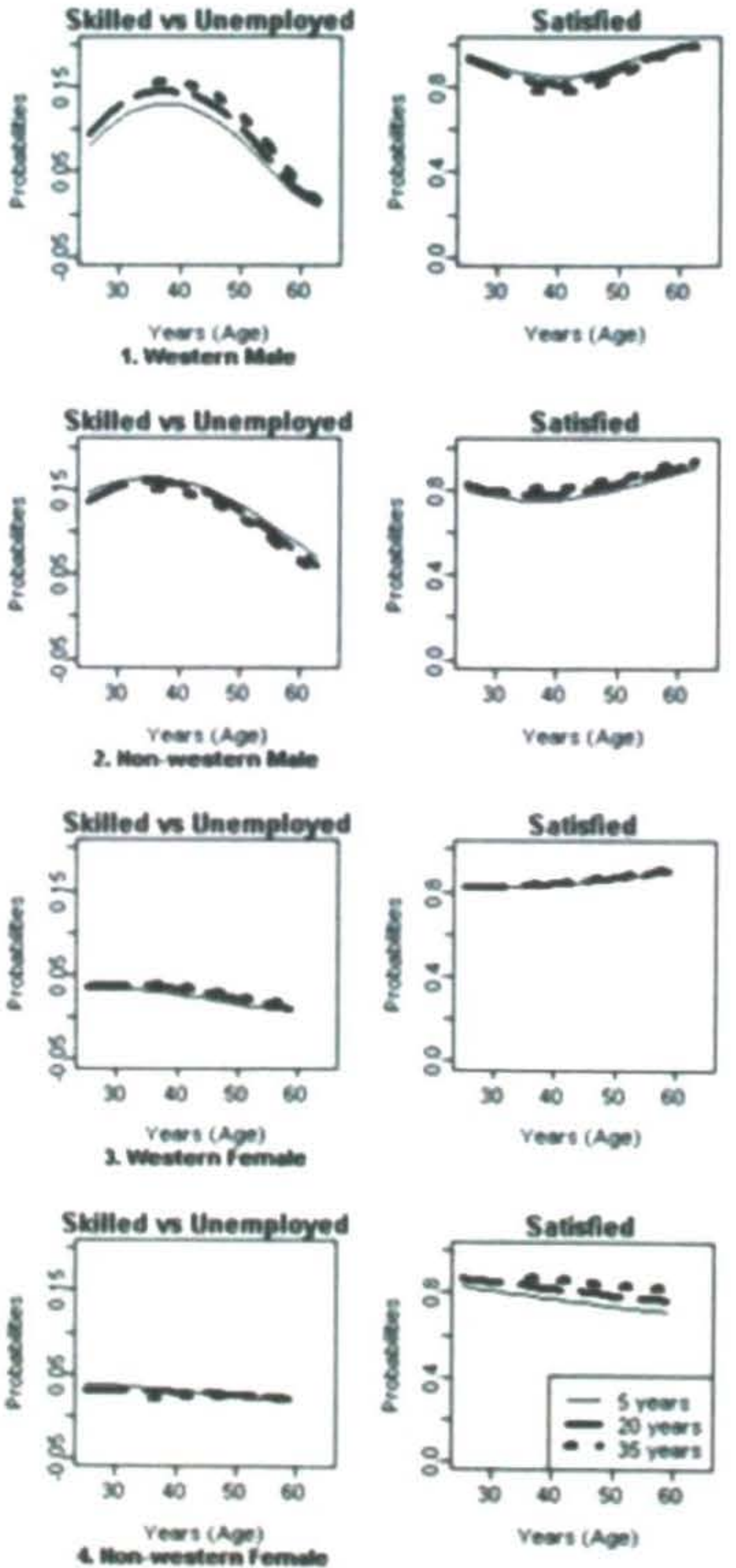
By contrast, non-Western males need time to adapt themselves into the mainstream culture and institutional setting in Australia. As shown by Figure 1, compared to their long-term counterparts, recent non-Western males are more likely to experience difficulties in the Australian labour market. At the same time, they are more likely to carry the social norms from their home countries, where employment status is important and social appraisal plays a centre role in their judgment about life satisfaction. ${ }^{13}$ Consequently, these two factors enlarge the discrepancy between labour market reality and career goals. Thus, compared to their Western counterparts, employment and career development may induce more concerns for the non-Western migrants, indeed, as shown by Figure 1, labour market outcomes have greater impact on their life satisfaction. Furthermore, the disparities between the Western and the non-Western males in subjective wellbeing and job-life relationship are more prominent among the young and the old. This may actually reflect the feeling of insecurity for these more socioeconomically disadvantaged non-Western groups. Nevertheless, as shown by Figures 2 , with longer duration in Australia, presumably, along with greater involvement in the Western culture, the non-Western make significant progress in the labour market and tend to develop a more relaxed attitude towards work. At the same time, their subjective wellbeing improves. As a result, the differences in subjective wellbeing and job-life relationship between the non-Western and the Western are more prominent for more recent migrants and reduce with duration in Australia (Figure 1).

Interestingly, as demonstrated in Figure 1, among male immigrants who have already been in Australia for 35 years, non-Westerners who migrated as teenagers (approximately younger than 15) and now age $35-45$ are likely to have better labour market achievement than their Western counterparts. They are also less likely to worry about employment and are more likely to declare a better life. This suggests that having Australian schooling help them integrate into Australian mainstream culture. Furthermore, the finding that the non-Western males are likely to outperform their Western counterparts if they migrate at teen age, suggests that the difficulties encountered by the non-Western in the labour market and life in general are more likely due to cultural barriers rather than race discrimination.

According to the existing literature, the disparity in subjective wellbeing between the Western and the non-Western may have several origins. Firstly, in non-Western countries where the collective culture dominates, one's personal desires are often subordinated to the expectations of other members in the society, while employment and occupation is highly regarded and is closely linked to social status of individuals. Therefore, the non-Western inferior labour market outcomes enlarge the goal-reality gap and a strong job-life relationship persists. Secondly, cultured backgrounds play a role in life satisfaction judgments as well. In Western individualist culture, psychological judgments such as subjective wellbeing are strongly affected by internal experience (Gilovich et al, 1998), which is related to the fact that Westerners tend to evaluate their life satisfaction more highly than non-Westerners do. ${ }^{14}$ Thirdly, ethnic minority status is related to feelings of alienation, and lower levels of access to societal resources. Hence the non-Western immigrants' wellbeing might have been hindered in the process of overcoming cultural discrepancies in everyday life. $^{15}$

\section{Conclusions}

A bivariate ordered probit random effects panel model is employed to investigate the assimilation processes of immigrants' subjective wellbeing and the role that labour market attainment plays in this process. The model controls for the direct contribution of the "bottom-up" factors to subjective wellbeing, such as housing, health, family and work, which are the domains that consistently affect happiness. In particular, the work domain is treated as endogenous by allowing the unobserved factors of labour market attainment and subjective wellbeing to be correlated, and the correlation of individual effects captures the "top-down" processes within the individuals' job-life relationship, which recognises the central role played by people's goals and dispositions. Using such a framework. we found that the "top-down" process seems to dominate both male and female immigrants' job-life relationship.

Labour market achievement has an significant positive effect on the subjective wellbeing of male immigrants. However, compared to the direct benefits from job, indirect effects that are associated with unobserved individual specific career goals play a more important role in the job-life relationship. The male immigrants who suffer greater discrepancies between career goals and the reality, are more concerned about job issues. They are those who are supposed to have a more successful career (judged by the human capital they possess), or are disadvantaged in other non-work life domains. For female immigrants, directly, the stress from work takes a toll on their life satisfaction. In particular, the well-educated female immigrants holding their career ambitions, find their subjective wellbeing is impeded by struggling over work-family balance. However, for most of the female immigrants, work may not be their central life interest, and play a trivial role in their subjective wellbeing.

As for the issue of cultural disparity between the Western and the non-Western, the non-Western males appear to be more concerned about employment and occupation. Labour market setbacks are compunded under a culture of emphasising social appraisal, which might have enlarged the discrepancies between career goals and reality. This contributes to inferior subjective wellbeing among non-Western male immigrants. Theoretically, cultural differences in evaluating life satisfaction and everyday experience of cultural adversity in Australia may also add to 
the disparity of subjective wellbeing between the Western and the non-Western. However, there are prominent adjustment effects for the non-Western male immigrants. With time, they do better in the Australian labour market, feel more satisfied with their lives, and employment issues poses much less risk to their subjective wellbeing. Interestingly, the pattern of these adjustment effects appear to be related to immigration age. The non-Western males who migrated before they became teenagers are likely to achieve higher labour market success and subjective wellbeing given sufficient duration in Australia. This suggests that racism does not play a role in non-Western immigrants' labour market and wellbeing assimilation.

This paper contributes to a relatively scare literature that stresses the important of individual heterogeneity in subjective wellbeing and job-life relationship. We exploit the simultaneously estimated bivariate system, and single out the groups who have job concerns based on the marginal effects of treatment effects. This analysis method is novel and may inspire other researchers to implement deeper analysis. We explore the labour market and wellbeing assimilation process of immigrants from different cultural backgrounds by jointly considering their age, immigration age and duration. The findings provide empirical evidence of how cultural factors play a role in the assimilation process. The amazing result we find for the work-happiness relationship for females using the bivariate random effects ordered probit approach is thought-provoking. It suggests that much work is needed for policies to be directed to help females maintain work-family balance. Our results also suggest the need to remove underlining barriers for the non-Western immigrants by understanding their culture. Although cultural difference inhibits the assimilation of the non-Western immigrants, the collectivist culture gives them momentum to strive for labour market success against adversity.

\section{Notes}

\section{At 30 June 2005 ABS07.}

2. Michalos (1985) finds that discrepancy between "reality and goal" has the most superior predictive power for subjective wellbeing among different types of interaction, and it is most successful in accounting for the variance in satisfaction with paid employment, while not as successful in other domains

3. The magnitude of that correlation is given by $\sqrt{\frac{\sigma_{L}^{2}}{1+\sigma_{L}^{2}}}$ and $\sqrt{\frac{\sigma_{S}^{2}}{1+\sigma_{S}^{2}}}$, respectively.

4. According to Michalos's (1985) Multiple Discrepancies Theory, life satisfaction is explained by the perceived discrepancies between the objective measures and the corresponding subjective goals and needs; and personality traits influence how these discrepancies are developed and how one would cope with them.

5. For a detailed discussion of the procedure and the properties of the GHK simulator, see Geweke (1989), Börsch-Supan and Hajivassiliou (1993), Hajivassiliou and Ruud (1994) and Keane (1994).

6. In HILDA, NESB immigrants have high attrition rate (Watson \& Wooden, 2004).

7. Duration $=$ Age - Immigration age. Duration in Australia is highly correlated with age, and its presence as an explanatory variable together with age will induce multi-collinearity.

8. Diener (1984) notes that, all subjective measures, such as family satisfaction, health satisfaction and job satisfaction, are affected by an individual's personality and are thus correlated with each other. Due to the same reason, they are very likely highly correlated with subjective wellbeing as well, and are arguably endogenous. Also, empirical economic studies normally employs an objective position based on observable choices made by individuals, such that inference can be made related to individual behaviour.

9. Based on both the estimated coefficients and predicted marginal effects of the two dummy variables for labour market outcomes (unskilled and skilled, with unemployed as the reference group)

10. These conditional probabilities are derived from the joint probabilities of the bivariate models at certain point in time (Equation 17), which do not involve the time-invariant components that only represent the variance across different time periods and have zero means. The first derivative of these joint probabilities on the parameters are also calculated, and the standard errors of the derived treatment effect probabilities are acquired using Delta method.

11. The standard errors of the marginal effects are calculated using Delta method. The marginal effects on other categories of labour market outcomes, subjective wellbeing and treatment effects are omitted due to limited space. They can be provided upon request.

12. Long (2005) also argues that educated women, who usually work in a skilled position, may assign a high priority and have high expectations for their jobs, and women in unskilled jobs may see work as a secondary concern to raising a family.

13. This role conflict can somehow be capture by the 
correlations between labour market outcomes and subjective wellbeing when education variables are only included in the labour market outcomes equation.

14. Culture provides individuals with the norms and values around which immigrants might allot different types of career goals to pursue, and work is a source of satisfaction only to the extent that it facilitates the pursuit of social goals. Ample evidence indicates that people from collectivist nations heavily emphasised social appraisal, and norms seem to play a more critical role as a standard for life satisfaction judgments among people in collectivist cultures than in individualist cultures (Markus \& Kitayama, 1991; Radhakrishnan \& Chan, 1997; Suh et al, 1998; Triandis, 2001).

15. Lyubomirsky \& Ross (1997) find that happy individuals rely more heavily on internal, subjective standards than on external social comparison information in self-evaluation processes.

16. Cross (1995) finds that students from a collectivist culture experience stress in the United States, and among them those who are more individualistic cope better in the cross-cultural adjustment process.

\section{References}

ABS (2007) 2005-2006 Migration-Australia, (3412.0) Australian Bureau of Statistics.

Andrews, F. M. and Withey S. R. (1976) Social Indicators of Well-Being. Plenum Press, New York.

Barnett, R. C. and Marshall, N. L. (1991) The relationship between women's work and family roles and their subject well-being and psychological distress, in M. Frankenhaeuser, U. Lundberg and Chesney, M. (ed) Women, Work, and Health, pp. 111-147, Plenum, New York.

Berk, R. and Berk, S. (1978) A simultaneous equation model for the division of household labor, Sociological Methods and Research, 6, 431-468.

Brickman, P. and D. T. Campbell (1971) Hedonic relativism and planning the good society, in $\mathrm{M}$. $\mathrm{H}$. Appley (ed.) Adaptation-level Theory, pp. 287-305, Academic Press, New York.

Börsch-Supan, A. and V. Hajivassiliou (1993) Smooth unbiased multivariate probability simulators for maximum likelihood estimation of limited dependent variable models, Journal of Econometrics, 58, $347-368$.

Clark, A., Etil, F. Postel-Vinay, F., Senik, C. and Van der Straeten, K. (2005) Heterogeneity in reported well-being: Evidence from twelve European countries, Economic Journal, 115(502), 118-132.

Clark, A. E. (2003) Unemployment as a social norm: Psychological evidence from panel data, Journal of Labor Economics, 21, 323-352.

Clark, A. E., Georgellis, Y. and Sanfey, P. (2001) Scarring: The psychological impact of past un-employment, Economica, 68, 221-241.

Cross, S.E. (1995) Self-construals, coping, and stress in cross-cultural adaptation, Journal of Cross-Cultural Psychology, 26, 673-697.

Cummins, R. A. (1996) The domains of life satisfaction: An attempt to order chaos, Social Indicators Research, 38, 303-328.

Diener, E. (1984) Subjective well-being, Psychological Bulletin, 95(3), 542-575.

Diener, E. and R. Lucas (1999) Personality and subjective well-being, in D. Kahneman, E. Diener and N. Schwarz (eds.) Well-being: The Foundations of Hedonic Psychology, pp. 213-229, Russell Sage Foundation, New York.

Diener, E., S. Oishi and R. E. Lucas (2003) Personality, culture, and subjective wellbeing: Emotional and cognitive evaluations of life, Annual Review of Psychology, 54, 403-425.

Diener, E. and E. Suh (2000) Culture and subjective well-being, MIT Press.

Diener, E., Suh, E. M., Lucas, R. E. and Smith, H. L. (1999) Subjective well-being: Three decades of progress, Journal of Personality and Social Psychology, 125(2), 276-302.

Geweke, J. (1989) Bayesian inference in econometric models using monte carlo integration, Econometrica, $57,1317-1339$.

Gilovich, T., Savitsky, K. and Medvec, V. H. (1998) The illusion of transparency: Biased assessment of other's' ability to read one's emotional states, Journal of Personality and Social Psychology, 75, $332-346$

Gruenberg, B. (1980) The happy worker: An analysis of educational and occupational differences in determinants of job satisfaction, The American Journal of Sociology, 86(2), 247-271.

Gutek, B, A., Nakamura, C. Y. and Nieva, V. F. (1981) The interdependence of work and family roles, 
Journal of Occupational Behaviour, 2(1), 1-16.

Hajivassiliou, V. and P. Ruud (1994) Classical estimation methods for LDV models using simulation, in R. Engle and D. McFadden (eds.) Handbook of Econometrics, vol. 4, pp. 2383-2441, Elsevier Science Publishers, Amsterdam.

Hawthorne, L. (1997) The question of discrimination: skilled migrants' access to Australian employment, International Migration, 35(3), 395-417.

Headey, B. and Wooden, M. (2004) The effects of wealth and income on subjective well-being and ill-being, Economic Record, 80, 24-33.

Keane, M. (1994) A computationally practical simulation estimator for panel data, Econo-metrica, 62, 95-116.

Long, A. (2005) Happily ever after? A study of job satisfaction in Australia, Economic Record, 81(255), 303-321.

Lucas, R., A. Clark, Y. Georgellis and E. Diener (2003) Re-examining adaptation and the setpoint model of happiness: Reactions to changes in marital status, Journal of Personality and Social Psychology, 84(3), 527-539.

Lyubomirsky, S. and Ross, L. (1997) Hedonic consequences of social comparison: Happy and unhappy people, Journal of Personality and Social Psychology, 73, 1141-1157.

Lyubomirsky, S. and L. Ross (1997) Hedonic consequences of social comparison: Happy and unhappy people, Journal of Personality and Social Psychology, 73, 1141-1157.

Markus, H. R. and Kitayama, S. (1991) Culture and the self: Implications for cognition, emotion, and motivation, Psychological Review, 98, 224-53.

Michalos, A. C. (1985) Multiple discrepancies theory, Social Indicators Research, 16(4), 347-413.

Miller, P. W. and Neo, L. M. (2003) Labour market flexibility and immigrant adjustment, Economic Record, 79(246), 336-356,.

Morse, N. C. and Weiss, R. S. (1955) The function and meaning of work and the job, American Sociological Review, 20(2), 191-198.

Pugliesi, K. (1995) Work and well-being: Gender differences in the psychological consequences of employment, Journal of Health and Social Behavior, 36(1), 57-71.
Radhakrishnan, P. and Chan, D. K. S. (1997) Cultural differences in the relation between self- discrepancy and life satisfaction. International Journal of Psychology, 32, 387-98.

Roxburgh, S. (1996) Gender differences in work and well-being: Effects of exposure and vulnerability, Journal of Health and Social Behavior, 37(3), 265-277.

Simon, R. W. (1995) Gender, multiple roles, role meaning. and mental health, Journal of Health and Social Behavior, 36(2), 182-194.

Shields, M. A., Price S. W. and Wooden M. (2007) Life satisfaction and the economic and social characteristics of neighbourhoods, Journal of Population Economics, 22 (2): 421-443.

Suh, E., Diener, E., Oishi, S. and Triandis, H. C. (1998) The shifting basis of life satisfaction judgments across cultures: Emotion versus norms, Journal of Personality and Social Psychology, 74, 482-493.

Triandis, H. C. (2001) Individualism - collectivism and personality, Journal of Personality, 69(6), 907-924.

Watson, N. and Wooden, M. (2004) Sample Attrition in the HILDA Survey, Australian Journal of Labour Economics, 7(2), 293-308.

Winkelmann, L. and Winkelmann, R. (1998) Why are the unemployed so unhappy? Evidence from panel data, Economica, 65(257), 1-15.

Witter, R. A., Okun, M. A., Stock, W. A. and Haring, M. J. (1984) Education and subjective well-being: A meta-analysis, Educational Evaluation and Policy Analysis, 6(2), 165-173.

\section{Author}

Weiping Kostenko

Research Fellow

Melbourne Institute of Applied Economic and Social

Reaearch

University of Melbourne

Parkville

Victoria 0310

Australia

Weiping.K@unimelb.edu.au 